\title{
Assessment of Selected Opinions of Agriculture Students of Rzeszow University in Poland, in the Context of Education for Sustainable Development in Rural Areas
}

\author{
Joanna Kostecka ${ }^{1}$ prof., Dr. habil.; Maria Cyrankowska ${ }^{2}$ MA; Agnieszka Podolak ${ }^{3}$ Ph.D. \\ Faculty of Biology and Agriculture, University of Rzeszow, Poland ${ }^{1,3}$ \\ Foreign Languages Centre, University of Rzeszów, Poland ${ }^{2}$ \\ jkosteck@ur.edu.pl ${ }^{1}$; m.cyrankowska@gmail.com ${ }^{2}$, mojaap@ poczta.fm ${ }^{3}$
}

\begin{abstract}
The article presents selected aspects of organizing sustainable development in rural areas, as well as a growing trend for personal development, highlighting the close relationship between the two. The aim of the present study was to analyse the opinions of chosen respondents, concerning their own motivation for implementing sustainable development, their willingness to learn and belief in their abilities - important aspects of effective and lifelong education in a knowledge-based society, for the good of the individual as well as the local and global community.
\end{abstract}

Agriculture students of the University of Rzeszów (Poland) were surveyed. They responded to 10 closed questions. They were motivated to implement sustainable development by changing their daily habits by knowledge about the increasing rate of biodiversity loss (32\%), knowledge of the poor quality of the environment (26\%) and economic incentives (29\%). They believed that in order to build a sustainable world the most needed were: information and knowledge (74\%) and responsibility (61\%) followed by ecological culture (48\%); they believed that self-knowledge and self-improvement were part of building sustainable development. As the most important thing, $65 \%$ of respondents indicated the constant search for a balance between self-care, caring for others and nature.

The results of the study provide a diagnosis of students' motivations and gives the concerned educators some hints how to conduct their classes and lectures. This is also significant as an aspect of organizing effective and long-lasting education, which is an important basis for implementation of sustainable development also in rural areas.

Keywords: sustainable development, personal development, rural areas, university education.

\section{Introduction}

The concept of sustainable development was formulated, accepted and introduced to the world vocabulary by the United Nations international bodies in 1992. It is now the basis for changes that lead to improved living and working standards of the communities around the world. It is a complex concept and includes equally valuable environmental, social and economic areas, which should be understood as fundamental and spread on further levels such as cultural, legal, organizational, moral, emotional and philosophical. The principles of building sustainable development must be continually presented and extended to youngsters, adults and elderly people - both in urban and rural areas. The latter in particular being usually valuable natural resources should be inhabited by people who care about the balance in natural and socio-economic development.

In the years 2004-2014, the World Decade for Education for Sustainable Development was implemented, and the Biological Diversity Decade has been launched for the period between 2011 and 2020. Due to the gravity of the problem, the issue of sustainable development should be known to the general public with a particularly compelling need to rescue ecosystems and biodiversity. The urgent need to stop biodiversity loss has been highlighted (Rockstrom et al., 2009; Kostecka, Cyrankowska, 2017).

Schools at different levels of education and universities must be involved in disseminating the knowledge. They should be supported by the actions of local governments, whose workers must be convinced of the need to slow down the biodiversity loss. Acceptance of responsibility for a broadly understood environment is a must, while involvement in this issue should also encompass businessmen and workers in the workplace, starting with engineers at the drawing boards developing innovative projects as part of the development of solutions for the broadly understood ecological engineering.

Other occupations crucial for the issue of sustainable development are those related to agriculture. The new participants in this space are educated in the field of agriculture at Rzeszów University. Their education should therefore be broad and effective. What makes education effective? As indicated by 
many studies (Glasser, 2010; Zimmerman, Bonner, Kovach, 1996; Robinson, 2010), it is to a large degree about students' intrinsic motivation, awareness and trust in their own efficacy and efficiency.

The aim of the present study was to analyse the opinions of the agriculture students of Rzeszów University, concerning their own motivation for implementing sustainable development, their willingness to learn and belief in their abilities - important aspects of effective and lifelong education in a knowledge-based society, for the good of the individual as well as the local and global community.

\section{Methodology}

The paper is based on a problem study and analysis of selected literature. The authors have also set themselves the goal of studying the opinions of agriculture students at the University of Rzeszów (Poland) on selected issues relevant in the context of sustainable development (SD).

A survey was conducted with 62 randomly selected students from $1^{\text {st }}, 2^{\text {nd }}, 3^{\text {rd }}$ and $4^{\text {rd }}$ years of Agriculture at the Faculty of Biology and Agriculture, University of Rzeszów. There were 26 women and 36 men participating.

They responded to the following 10 closed questions: (1) What motivates you to implement sustainable development by changing your daily habits? (2) What do you think is needed to build a sustainable world? (3) Which option is most important to you? (4) Do you feel the need for continuing education? (5) Is building sustainable development of your own environment a priority in your life? (6) Do you think that self-knowledge and self-improvement are part of building sustainable development? (7) How do you understand self-improvement? (8) Do you think you have the power to build sustainable development? (9) What is your current average grade of studies? (10) Would you like your average grade to be higher?

The responses had been analysed and then presented in tables and a graph (in percentages). The percentages are calculated in relation to the number of subjects in the groups of males (M) or females (F) and the total of all respondents.

\section{Results and discussion}

Restrictive use of natural resources is nowadays difficult to accept by many people and strictly respected after previous legal imposition, could foster a number of conflicts.

As the results of the survey show, what motivates the respondents to implement sustainable development by changing their daily habits are the following factors: knowledge about the increasing rate of biodiversity loss (32\% of indications), knowledge of the poor quality of the environment (26\%) and economic incentives $(29 \%)$. The responses of men and women were similar (Table 1).

Table 1

The respondents' answers about their motives to implement sustainable development by changing their daily habits (general and gendered)

\begin{tabular}{|l|c|c|c|}
\hline \multirow{2}{*}{ Motives } & \multicolumn{3}{c|}{ Distribution of responses (\%) } \\
\cline { 2 - 4 } & M & F & Total \\
\hline Law enforcement in this regard & - & - & - \\
\hline Knowledge of the poor quality of the environment & 28 & 23 & 26 \\
\hline Examples of other members of society & 16 & 8 & 13 \\
\hline Knowledge of the increasing rate of the biodiversity loss & 28 & 38 & 32 \\
\hline Economic incentives & 28 & 31 & 29 \\
\hline Other (what) & - & - & - \\
\hline
\end{tabular}

The surveyed students believed that in order to build a sustainable world the most needed were: information and knowledge (74\%) and responsibility $(61 \%)$ followed by ecological culture (48 \%), social culture and openness to other perspectives and openness to other values (Figure 1). The fewest of them appreciated self-knowledge and self-reliance. The surveyed women most differed from the surveyed men in their attitude towards self-awareness (this trait was chosen as an important factor by over twice as many women as men). 
A

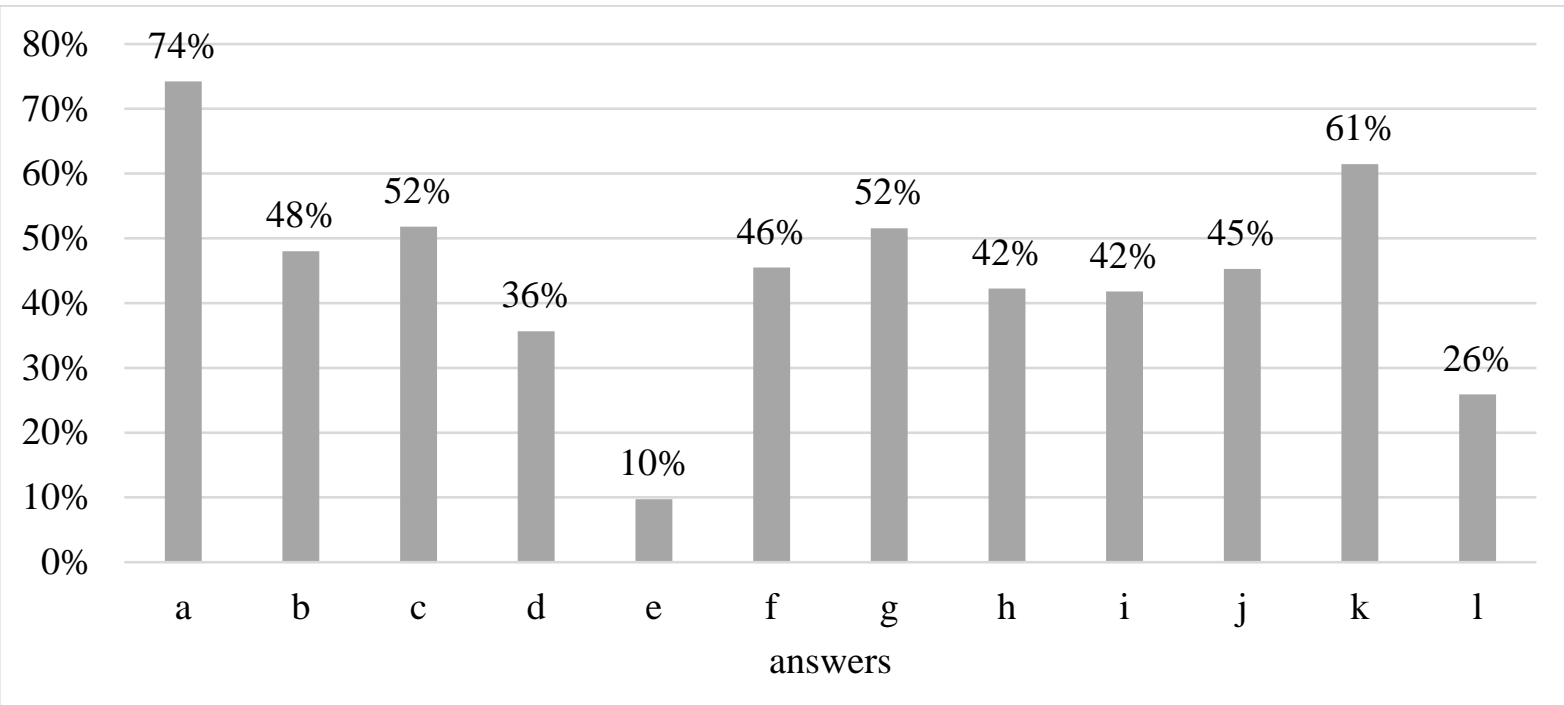

\begin{tabular}{|c|c|c|c|}
\hline \multicolumn{2}{|l|}{ B } & $\mathbf{M}$ & $\mathbf{F}$ \\
\hline $\mathrm{a}$ & - information and knowledge & 78 & 69 \\
\hline $\mathrm{b}$ & - ecological culture & 39 & 62 \\
\hline $\mathrm{c}$ & - $\quad$ social culture & 56 & 46 \\
\hline $\mathrm{d}$ & - economic culture & 39 & 31 \\
\hline $\mathrm{e}$ & - $\quad$ self-knowledge & 11 & 8 \\
\hline $\mathrm{f}$ & - $\quad$ self-awareness & 56 & 31 \\
\hline $\mathrm{g}$ & - openness to another point of view & 44 & 62 \\
\hline $\mathrm{h}$ & - openness to other values & 28 & 62 \\
\hline $\mathrm{i}$ & - openness to change your views & 33 & 54 \\
\hline $\mathrm{j}$ & - openness for a change of lifestyle & 39 & 54 \\
\hline $\mathrm{k}$ & - responsibility & 56 & 69 \\
\hline 1 & - $\quad$ self-reliance & 28 & 23 \\
\hline
\end{tabular}

Figure 1. The respondents' answers about factors needed to build a sustainable world [\%] (A - total; B - males and females).

As the most important thing, the largest group of respondents (women and men alike) indicated the constant search for a balance between self-care, caring for others and nature (65\% in general) (Table 2). Only women selected taking care of others (Table 2).

Table 2

Opinions of respondents about the balance between caring for oneself, others and nature

\begin{tabular}{|l|c|c|c|}
\hline \multirow{2}{*}{ Criteria } & \multicolumn{3}{|c|}{ Distribution of responses (\%) } \\
\cline { 2 - 4 } & $\mathbf{M}$ & $\mathbf{F}$ & Total \\
\hline Taking care of yourself & 17 & 15 & 16 \\
\hline Caring for others & - & 15 & 6 \\
\hline Caring for nature & 11 & 15 & 13 \\
\hline $\begin{array}{l}\text { Constant search for the balance between those } \\
\text { mentioned above }\end{array}$ & 72 & 55 & 65 \\
\hline
\end{tabular}

Analysing results from the study data "definitely yes" and "yes" are counted together. The students surveyed claimed that building sustainable development of their closest environment was one of their important priorities (56\% of men and $61 \%$ of women) (Table 3). This was mainly the response of older students who had the opportunity to consider the issues of sustainable development in several successive 
courses (philosophy of nature, ecology and environmental protection, waste management, agribusiness and sustainable rural development). This is because one of the authors of the article had the opportunity to have more than 10 years of experience with UNEP and UNESCO educational programs (CCN, 2006; PERL, 2017) and learn about sustainable development. She also gained a deep belief in the importance of education in this area.

The respondents believed self-knowledge and self-improvement were part of building sustainable development (77\% of men and $77 \%$ of women) and felt the need for continuous education $(61 \%$ of men and $62 \%$ of women) (Table 3). Half of the surveyed men (50\%) and women (46\%) thought they had the power to build sustainable development.

Table 3

Respondents' answers to the subsequent questions of the survey (gendered)

\begin{tabular}{|c|c|c|c|c|c|c|c|c|}
\hline \multirow{3}{*}{ Indicator } & \multicolumn{8}{|c|}{ Question and distribution of responses (\%). } \\
\hline & \multicolumn{2}{|c|}{$\begin{array}{l}\text { Is building sust- } \\
\text { ainable develop- } \\
\text { ment of your own } \\
\text { environment a } \\
\text { priority in your } \\
\text { life? }\end{array}$} & \multicolumn{2}{|c|}{$\begin{array}{l}\text { Do you think that } \\
\text { self-knowledge } \\
\text { and self-impro- } \\
\text { vement are part of } \\
\text { building sustain- } \\
\text { able development? }\end{array}$} & \multicolumn{2}{|c|}{$\begin{array}{l}\begin{array}{l}\text { Do you feel the } \\
\text { need }\end{array} \\
\text { for } \\
\text { continuous } \\
\text { education? }\end{array}$} & \multicolumn{2}{|c|}{$\begin{array}{l}\text { Do you think you } \\
\text { have the power to } \\
\text { build sustainable } \\
\text { development? }\end{array}$} \\
\hline & $\mathbf{M}$ & $\mathbf{F}$ & M & $\mathbf{F}$ & M & $\mathbf{F}$ & $\mathbf{M}$ & $\mathbf{F}$ \\
\hline Definitely yes & 6 & 15 & 22 & 38 & 17 & 31 & - & - \\
\hline Yes & 50 & 46 & 55 & 39 & 44 & 31 & 50 & 46 \\
\hline I do not know & 33 & 31 & 17 & 15 & 28 & 31 & 50 & 46 \\
\hline No & 11 & 8 & 6 & 8 & 11 & 7 & - & 8 \\
\hline Definitely not & - & - & - & - & - & - & - & - \\
\hline
\end{tabular}

It should be emphasized here that not only senior students thought so. First and second year students have contact with the second author of the article - an English tutor. The co-author of this article pays great attention to presenting students with personal development issues. It seems that what she does makes sense, and the answers to the question: How do you understand self-improvement? (shown in Table 4) appear to be consistent with the answers to the previous question. Among the proposed answers, the students chose mainly: gaining new information (49\%) and increasing knowledge (39\%) (Table 4).

Table 4

Respondents' awareness of self-improvement

\begin{tabular}{|l|c|c|c|}
\hline \multirow{2}{*}{ Criteria } & \multicolumn{3}{|c|}{ Distribution of responses (\%) } \\
\cline { 2 - 4 } & M & F & Total \\
\hline Physical development & 6 & - & 3 \\
\hline Obtaining new information & 49 & 46 & 49 \\
\hline Growth of knowledge & 39 & 38 & 39 \\
\hline Spiritual development & - & 8 & 3 \\
\hline Other (what) & 6 & 8 & 6 \\
\hline
\end{tabular}

Interpreting subsequent questions of the survey (Table 5), it can be emphasized that among the respondents the majority of the students were quite ambitious ( $72 \%$ male and $92 \%$ female).

As urgent as it is, the organization of social life in line with the concept of sustainable development, including the effect of slowing down the use of natural resources and biodiversity protection (Kostecka, 2013), cannot be achieved too quickly because it cannot be enforced against the currently existing trends. A number of actions are being taken to develop healthy ecosystems and restore their function, and above all, to raise people's awareness and foster their attitudes to allow for the strategic protection of ecosystem services. Farmers, as properly educated users of the environmentally valuable rural areas, must also support these actions. 
Distribution of responses to the final questions of the survey (\%)

Table 5

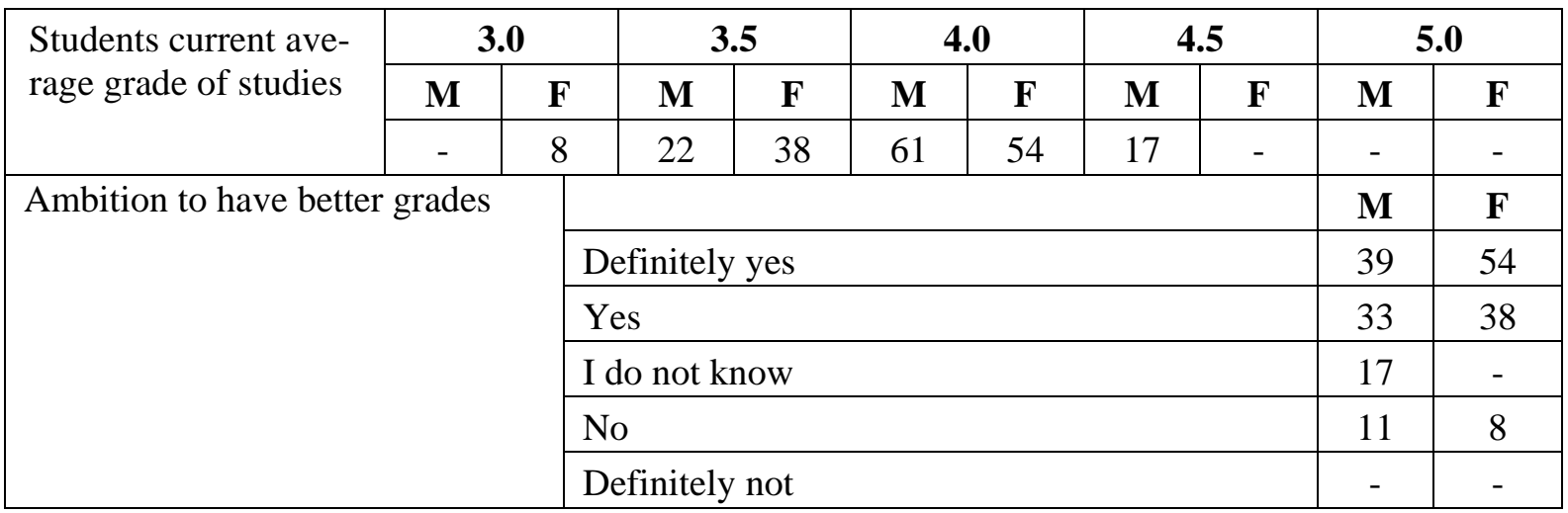

Due to the need to exchange experiences with foreign partners in the field of building sustainable development, what is vital is not only knowledge of sustainable development but also language education (Kostecka, 2012; Kostecka, Cyrankowska, Piersiak, 2016) and consumer education (Kostecka, Mazur, 2012).

In the flood of information, it is easy to miss what is important. Is contemporary education adapted to the changing world, and does the university prepare competent staff to meet the challenges of the 21 st century? Does it develop personality and creativity (Robinson, 2010), does it inspire self-learning (Zimmerman, Bonner, Kovach, 1996), does it stimulate thinking and sense of responsibility for one's own conduct, does it indicate ways of effective learning and problem solving, how about stress management or time management? Is it possible to develop a healthy sense of self-efficacy in young people (Zimmerman, Bonner, Kovach, 1996), and consequently their self-esteem and self-confidence? In addition to imparting current knowledge of high quality and usefulness, university education should also develop the desire to learn and build self-awareness and social knowledge, as well as good interpersonal relationships based on mutual trust and respect (Glasser, 2010).

\section{Conclusions}

The current publication describes selected opinions of students of Agriculture studying at the University of Rzeszów in Poland, in the context of education for sustainable rural development. It provides a diagnosis of its selected features and gives the concerned educators some hints on how to conduct the classes and lectures in the future. It seems that the students participating in the research, having some contact with the issues of sustainable development in different contexts during their educational cycle, have acquired the right understanding of the term and its elements. The results of the survey also clearly show that the students see a clear link between self-growth and care for sustainability, both of which complement each other and involve people's awareness, openness and responsibility.

When planning subsequent research, one could wonder if the positive traits depicted in the results of the present survey are only surface-like and short-lived or are they the foundation for a deeply rooted ecological / sustainable development culture? It would also be interesting to see the results of the survey of students of another university, whose lecturers did not have the opportunity to study the principles of sustainable development for over 10 years and acquire the profound conviction of the importance of education in this field.

During the 1st World Summit on Sustainable Development in Rio de Janeiro in 1992, the leaders of most countries pledged to implement sustainable development into the organisation of social and political life. However, 25 years have passed and most people in the world have not heard of this way of organizing social life - let alone its active implementation. 


\section{Bibliography}

1. CCN. The Consumer Citizenship Network. (2006). Retrieved from www.eesc.europa.eu/sites/default/files/resources/docs/pp_thoresen.pdf

2. Glasser W. (2010). Every Student can Succeed. Chatsworth, CA: William Glasser.

3. Kostecka J. (2012). Selected Proposals for Including the Issue of Sustainable Development in the Content of Teaching in English. In Didactics at Higher Education Institutions - Efficiency of New Methods of Education. Rzeszow: Mitel, 65-75.

4. Kostecka J. (2013). Self-evaluation on the Way to Retardation of Pace Life and Resources Transformation. Problems of Sustainable Development, 8(2), 93-102. Retrieved from http://ekorozwoj.pol.lublin.pl/no16/l.pdf

5. Kostecka J., Cyrankowska M. (2017). Readiness for Applying Innovations Promoting Retardation of the Pace of Resources Transformation in Rural Areas. In V. Dislere (Ed.), The Proceedings of the International Scientific Conference Rural Environment. Education. Personality, 10, Jelgava: LLU, TF, 100-106. Retrieved from http://lufb.llu.lv/conference/REEP/2017/Latvia-UnivAgricult-REEP-2017_proceedings-100-106.pdf

6. Kostecka J., Cyrankowska M., Piersiak A. (2016). Active Teaching/learning as Urgent Need in Contemporary Education for Sustainable Development. In V. Dislere (Ed.), The Proceedings of the International Scientific Conference Rural Environment. Education. Personality, 9, Jelgava: LLU, TF, 337-354. Retrieved from http://llufb.llu.lv/conference/REEP/2016/Latvia-Univ-AgricultREEP-2016proceed2255-808X-337-354.pdf

7. Kostecka J., Mazur B. (2012). Chosen Attitudes of Polish Consumers During the Decade of Education for Sustainable Development. Inzynieria Ekologiczna. 28, 131-143. Retrieved from http://www.archive.ineko.net.pl/pdf/28/12.pdf

8. PERL. The Partnership for Education and Research about Responsible Living. (2017). Retrieved from http://www.perlprojects.org

9. Robinson K. (2010). Bring on the Learning Revolution. Retrieved from https://www.youtube.com/watch?v=r9LelXa3U_I

10. Rockstrom J., Steffen W., Noone K., Person A., Chapin S.F., Lamin E.F., Lenton T.M., Scheffer M., Folke C., Schellnhuber H.J., Nykvist B., de Wit C.A., Hughes T., van der Leeuw S., Rodhe H., Sörlin S., Synder P.K., Costanza R., Svedin U., Falkenmark M., Karlberg L., Corelli R.W., Fabry V.J., Hansen J., Walker B., Liverman D., Richardson K., Crutzen P., Foley J.A. (2009). A safe operating space for humanity. Nature, 461(24), 472-475. Retrieved from https://www.researchgate.net/publication/44160502_A_safe_operating_space_for_humanity

11. Zimmerman B.J., Bonner S., Kovach R. (1996). Developing Self-Regulated Learners: Beyond Achievement to Self-Efficacy. Washington DC: American Psychological Association. 